\title{
Hydrological analysis of Unzen volcanic aquifer
}

\author{
REIKA YOKOCHI ${ }^{1}$, ROLAND JOSEF PURTSCHERT ${ }^{2}$, \\ YOSHIMITSU SUDA ${ }^{3}$, NEIL C STURCHIO ${ }^{4}$ AND JÜRGEN \\ SÜLTENFUSS 5
}

${ }^{1}$ The University of Chicago

${ }^{2}$ University of Bern

${ }^{3}$ Nagasaki University

${ }^{4}$ University of Delaware

${ }^{5}$ University of Bremen

Presenting Author: yokochi@uchicago.edu

Mt. Unzen is a polygenetic volcano located in the graben structure of Shimabara peninsula, southwest Japan. Three geothermal fields within the Unzen graben are characterized with clearly distinct water types, reflecting different processes involved in generating the geothermal fluids. The origin of water contributing to these volcanic aquifer systems is crucial information for understanding the development of the geothermal system. Here we report water stable isotopic compositions and tritium activities of geothermal fluids in the Unzen geothermal field, two geothermal source wells in Shimabara region, a mineral spring and a shallow well in Obama region.

The stable isotope compositions of low temperature fluids fall on or close to the local meteoric water line defined by Mizota and Kusakabe (1994) based on the $\delta \mathrm{D}-\delta^{18} \mathrm{O}$ spatial distribution of surface water and shallow groundwaters in Japan. The tritium activities of samples from Shimabara geothermal wells were close to background level. A low tritium activity $(<0.5 \mathrm{TU})$ was also reported in a previous study at one of the wells (Kawabe, 1997). Both data indicate pre-nuclear recharge of the geothermal fluid (<1955), but our sample collected in $2019(0.0+/-0.05$ TU) nearly doubles the lower limit age of the water compared to the previous one collected in 1993. The water samples from the Unzen geothermal field are linearly correlated with a slope of 3.4 on a $\delta \mathrm{D}-\delta^{18} \mathrm{O}$ plot, deviating from the local meteoric water line. All but one samples from the Unzen geothermal field had relatively high ( $>1 \mathrm{TU}$ ) tritium activity, indicating a significant contribution of young water probably from the precipitation within the surface watershed. A high temperature frying-pan type feature had only trace tritium activity, indicating the presence of conduits that enabling older (pre-nuclear) heated/steam water to ascend without mixing with shallow groundwater. Based on the analyses of a hydrograph, Tabata (1960) reported correlations among the temperature of the geothermal fluid, the fluid flux, and time-ramped sum of the local precipitation. The observation is consistent with the mixed origin of the geothermal fluid, with a near-constant flux of geothermal fluids mixing with varying quantities of cold surface water. 